\title{
A case of physics faculty engaging in pedagogical sense-making
}

\author{
Chandra Turpen, ${ }^{1}$ Alice Olmstead, ${ }^{2}$ and Hannah Jardine ${ }^{3}$ \\ ${ }^{1}$ University of Maryland, Dept. of Physics, Toll Physics Building, College Park, MD 20742 \\ ${ }^{2}$ University of Maryland, Dept of Astronomy, 1113 Physical Sciences Complex, College Park, MD 20742 \\ ${ }^{3}$ University of Maryland, Dept. of Teaching and Learning, \\ Policy and Leadership, 2311 Benjamin Building., College Park, MD 20742
}

\begin{abstract}
Faculty often become motivated to try research-based instructional strategies after attending profes-sional development (PD) workshops, but are often underprepared to wisely adapt these strategies both to their local contexts and to specific situations they encounter with their students. We used our workshop observation tool to select a rare session from the Physics and Astronomy New Faculty Workshop where faculty are analyz-ing instruction within a large group open discussion. We analyze video-recordings of this session to understand what it can look like for faculty to learn how to reason about instruction in ways that would support their flexible response to students' reasoning and engagement in the moment. Our analysis identifies features of pedagogical sense-making and considers what might support its emergence in this situation.
\end{abstract}

\section{INTRODUCTION}

The physics education research community has a long history of both developing instructional strategies that improve student outcomes [1], and working to prescriptively disseminate these strategies to other physics educators assuming they will be adopted as is [2]. Indeed, this change approach has succeeded at building faculty awareness and motivation to try these strategies [3]. However, a dissemination approach alone is insufficient for helping faculty to learn how to flexibly adapt instructional strategies based on students' reasoning and engagement. The change approach of "developing reflective teachers" is better suited for these goals [2].

At the K-12 level, scholars have proposed clear visions for quality science teaching which involve teachers: noticing and attending to the substance of students' ideas [4-7], evaluating instructional choices based on concrete observations of classroom events or specific hypothetical scenarios, and linking instructional choices to education research principles [8, 9]. Scholars have also proposed designs for K-12 teacher PD experiences that would support these visions [10]. For the purposes of this analysis, we will refer to such reasoning as "pedagogical sense-making", i.e., educators pursuing robust pedagogical logic based on their observations and interpretations of classroom events and, in particular, how they see instructional moves as plausibly affecting students' engagement. We see these visions as equally relevant for college physics faculty.

Little research, however, has been done to study faculty engaging in pedagogical reasoning within PD settings. Physics faculty have largely experienced traditional instruction as students [11] and receive little to no pedagogical training beyond this. They typically encounter few opportunities to collaboratively reason about teaching, often making day-to-day instructional decisions in isolation [12]. With the potentially different incoming expectations and pedagogical training of college faculty, it is unclear if and when physics faculty will engage in rich pedagogical discussions. In this paper, we investigate what pedagogical sense-making can look like and what aspects of a situation may support its emergence.

\section{THEORETICAL FRAMEWORK}

Some researchers have thought of faculty thinking in terms of robust, unitary instructional beliefs [13]. We, however, start with the theoretical stance that faculty thinking is often highly variable across contexts. Therefore, we expect faculty to have a variety of ways of organizing activities for the learning of others and expect that, in some contexts, faculty will have access to and draw on highly constructivist resources [14]. For example, we think faculty likely bring more constructivist resources to bear on teaching their kid to ride a bike or mentoring a graduate student within their research lab, even if these resources may be less commonly elicited when reasoning about their classroom settings. The idea that faculty hold many potentially productive ideas that may be cued up in different contexts, and that PD leaders could help faculty to refine and reorganize these ideas, centrally informs how we orient to faculty thinking and learning. Looking for the complexity and richness of existing ideas held by faculty can help us to respectfully understand (as researchers) and try to build from (as PD leaders) where faculty are starting from.

We also broaden our view to take up theoretical elements from Vygotsky and the many scholars who have interpreted and expanded on his work [15-18]. From a Vygotskian perspective, interactions with others and physical tools can serve as mediators of thought, and should be considered an integral (and inseparable) part of thinking and learning - it is not useful to divorce cognition and action $[15,19]$. While individuals' thoughts play a role in their learning, the interactions of people with tools, and people with other people, are the developmental precursors of what will later be internalized by individuals. This perspective suggests that modeling the form and structure of distributed cognitive processes can give us insight into what faculty will take away from these interactions: they are a part of the learning process and deserve significant attention. During PD, faculty reasoning and engagement is situated in workshop sessions, and thus depend on aspects of the context such as: what ideas faculty are encouraged to 
contribute, how workshop activities are launched, what tasks faculty are asked to engage with, how faculty interact with each other, and what workshop leaders say or do to facilitate interactions between participants. These theoretical commitments inform our data selection and data analysis.

\section{METHODOLOGY}

In our prior work, we have developed an observational tool [20] to capture in real-time the form and focus of faculty engagement within workshops using the Physics and Astronomy New Faculty Workshop (NFW) as our primary research site. This 4 -day workshop is broken into many $\sim 1$-hour sessions, the majority of which are focused on specific researchbased instructional strategies. Attendees are largely in their first 1-3 years of teaching at the university and have a wide range of instructional experiences, with at least half of all participants reporting no experience using research-based instructional strategies [21]. Using coded data from our tool, we could quickly recognize sessions where faculty spent a significant fraction of time analyzing instruction within open whole group discussions and small group discussions. For this analysis, we deliberately selected a rare case within our extensive database of video-recordings of the NFW (N $\sim 51$ sessions); specifically, we consider an episode of large group discussion among approximately twenty faculty where we hear many different ideas being voiced.

Here we present a case study of faculty engaged in discourse around instruction [22]. In the focal session, faculty analyze a segment of classroom video guided by: a transcript, a representation of the task that students in the video are working on, and brief written guiding questions. This activity is taken from a library of video resources and associated activities known as Periscope [26]. These activities were designed to help instructors practice noticing and interpreting student behavior and apply lessons they have learned about teaching to actual teaching situations, thus developing their "professional vision" [4] of what it means to be a teacher [6]. From our data set, this session struck us as exemplary and we sought to externalize what impressed us about it. In our analysis, we draw on literature on effective teacher conversations $[8,9]$ and take into account key features of students' scientific sense-making [23, 24]. In this paper, we ask: In what ways are faculty engaging in pedagogical sense-making, and what structural features might be supporting or sustaining this engagement?

\section{ANALYSIS}

The workshop leader (WL) launches the video lesson by asking faculty to read and discuss the task that students in the video will be working on. By doing this, she gives faculty time to make sense of the physics task and consider ideas that students might have related to it. After letting faculty discuss in small groups, she plays the video, stating 'I'm just gonna ask you afterwards to talk with your partner about what you noticed, very open ended question." She plays the 3-minute video in which a physics TA (Levi) interacts with a group of students who are working on a physics Tutorial about how pressure operates in fluids. After watching the video, faculty discuss with their partners for a few minutes. In one small group discussion, we see evidence of faculty using the guiding questions on the handout to direct their conversation towards more refined observations and interpretations of classroom events. Faculty refer to specific student statements in the transcript to elaborate on and clarify their arguments. For example, one faculty participant states "Yeah I'm just reading the transcript...Like in line 16, she says..." After the few minutes of small group discussion, the WL begins a follow-up conversation with all participants as represented in the transcript found in Table I.

Overall, we find this to be a rich conversation. First, multiple faculty participants are evaluating instruction and providing pedagogical justifications to support their evaluation. Most faculty notice aspects of and make evaluative statements about the TA's instructional moves, such as, "I like the way Levi..." (9), "one thing I really appreciated..." (11), and "we noticed that what was also good about the TA..."(12). Several faculty notice and praise the fact that the TA does not say anything when he first sits down with the students, and instead waits until they ask a question $(2,4,11,12)$. Similarly, faculty notice and praise the fact that the TA does not tell students the answer but rather tries to pull students into the discussion (9) and encourages students to "come up with some kind of claim by themselves" (12) and "tackle this problem with our brains and think about it" (10). We also notice that faculty seem to be listening to and leveraging the ideas voiced in this large group discussion to some extent, e.g., "like you said..." (11), which suggests that at least some faculty are carefully listening to their peers and possibly learning from them.

Faculty also notice aspects of students' reasoning and engagement that could support them in thoughtfully responding to students and facilitating group work in their own classrooms. For example, faculty $\mathrm{C}$ suggests that students may not recognize each other's expertise because of the way they choose to interact with each other (6). Faculty D notices when another student says very little (9), and identifies a specific instructional move on the part of the TA ("You seem to disagree, to what do you disagree?") that may have ameliorated this collaboration challenge. While faculty do not explicitly state in this moment that these ideas are applicable or relevant in other situations, we see how ideas could be generalized to noticing and responding to student behavior in similar situations. Faculty may recognize these similarities or could be guided to do so.

What the WL says and does in this session also may have influenced the emergence of pedagogical sense-making. The prompt that initiates this large group discussion (1) is very open ("What'd you see?"), which matches the initial prompt that launched faculty small group discussions earlier. When faculty A responds with an observation of the TA's behavior, the WL responds with another open, follow-up prompt 
TABLE I. Transcript of large group discussion among physics faculty facilitated by a workshop leader (WL). The left hand columns indexes talk turns for reference within the body of the text.

1 WL: Okay, I'd love to hear what you got. Let's come back. (Faculty become quiet.) What'd you see?

2 A: He didn't say anything right away, Levi didn't. He waited a solid thirty seconds maybe before he jumped in.

3 WL: What'd you think of that?

4 A: I think that's probably a good thing to at least understand what the discussion (is), from his perspective.

5 (Faculty B makes a comment about the complexity of the prompt and the WL responds, not shown for brevity)

6 C: It kinda surprised me, that it seemed like one student clearly knew what was going on and could have helped the others. And she did, but it sorta surprised me that she was being polite about it and not so much saying "Listen you're wrong this is how you should be thinking about this." She was kinda giving them equal time. And so it was hard, it was probably hard for the other students to realize "Oh she actually know actually knows what's going on and she's maybe just being polite."

7 WL: That was Alicia, or Cass?

8 C: I think it was Alicia.

9 D: Cass is interesting one because she might be the one that understands the most, but she's not saying it. It's difficult to understand whether even she is understanding or not, because she's not participating. And I like the way Levi tried to bring her, like, "You seem to disagree, to what do you disagree?" So he's trying to bring Cass into the discussion.

10 E: So it seemed like there was definitely some definitional issues that the students were dealing with, and maybe that came from lecture, and we don't know what happened in lecture so we don't know if the professor just did a poor job or if it was intentional, but what I liked was that Levi just put it aside. He was like "Lecture's not, I wasn't in lecture, Let's just tackle this problem with our brains and think about it," which I thought was really great, and then you're not kinda hinging everything on what the professor said in class.

11 F: I think one thing I really appreciated was he came and sat down and didn't say a single word until one of the students said "I have a question", and then like you said he didn't introduce anything he just waited until "I have a question."

12 G: We noticed that what was also good about the TA was he didn't tell them the answer, but instead guided them to formulate their claim in a complete sentence, so he guided them into formulating their idea even though it was wrong, and refrained from teaching them anything apart from helping them to come up with some kind of claim by themselves.

13 WL: Was anyone concerned about that, that he was helping them guide the formulation but it wasn't going to be correct necessarily?

14 A: Maybe a little. I mean I noticed at one point he repeated back some specific language that they used, and that's probably not how I would describe it and I'm not sure it's a great way to describe it so I don't know if, I don't know if maybe he should have tried to steer them in a different direction.

("What'd you think of that?") that invites faculty A to evaluate this behavior himself. Following this, we note that the WL says very little for several turns of talk, simply acknowledging and calling on faculty to voice their ideas without interjecting her own ideas, and helping faculty to clarify their thinking for others (e.g.,"That was Alicia, or Cass?" - 7). It is only at the very end of this interaction that the WL substantively alters the flow of the conversation (13) by providing a reason that faculty might disagree with one another and inviting them to voice opinions along these lines. In this last case, it seems that the WL gives faculty social permission to disagree both with one another and with the TA's decision in the video, which one faculty member takes up.

Though we have only analyzed one case of faculty engaging in pedagogical sense-making in a context where they are watching and analyzing classroom video together, we think that it is valuable to speculate on what may have supported the emergence of this activity. In a broad sense, because this is a teaching-focused workshop, faculty are likely coming to this session expecting to learn about instruction. While it is difficult to build strong conjectures about what features of these specific situations influence faculty engagement, it is plausible to us that the following aspects of the session's structure may matter: (a) the video is relatively short, focused on a conceptually rich student task with accessible and relevant disciplinary content, and includes rich interactions among students and between students and an educator; (b) clear driving questions prompt faculty to reflect on what they see happening (both through the handout and verbal reminders); (c) faculty are given dedicated time to make sense of the physics in small groups; (d) faculty are given dedicated time to make sense of their initial impressions of the classroom episode in small groups, with transcript provided; (e) the WL's facilitation moves invite faculty to share and elaborate on their own ideas and respond to each other's ideas. In this way, the WL's specific framing of the session, and the framing of the entire workshop at large, may have played a role in their openness to having these types of conversations.

\section{DISCUSSION}

Though we do not consider this to be a defining feature of pedagogical sense-making, it is worth noting that much of the reasoning we observe is consistent with education research principles (such as constructivism). Some researchers and PD leaders might characterize these new faculty as hav- 
ing conceptions of teaching as telling and not expect them to voice these ideas [13]. This case demonstrates that it is indeed possible for constructivist resources to emerge in faculty PD settings with junior faculty.

Secondly, our findings show that faculty are capable of having productive evidence-based conversations around pedagogy. This analysis highlights several things that make this pedagogical conversation productive: (a) sharing a diversity of viewpoints publicly, (b) noticing student reasoning and behaviors within classroom moments, (c) noticing instructor behaviors within classroom moments, (d) grounding pedagogical logic in concrete classroom events, and (e) building claims about the potential effects of instructional moves on students' participation. We recognize that this is only an initial first step toward fleshing out a framework for thinking about faculty engagement in pedagogical sense-making. We hope that by sharing this analysis we inspire other scholars to build additional cases toward understanding the nature of pedagogical sense-making. We imagine that a particularly fruitful next step would be to seek out cases where educators are debating, comparing, contrasting, and refining pedagogical logic, where a diversity of thinking gets put out on the table and leads to a generative discussion. In developing such cases, we encourage others to investigate not just PD settings, but also other professional settings where collaborative instructional change efforts are being pursued (such as team-based course transformation efforts, discipline-based education re- search groups, departmental action teams [25], or campusbased faculty learning communities).

We think that conversations around pedagogical sensemaking are likely to support faculty in being able to flexibly adapt strategies to instructional situations (responding to students in moment-to-moment ways in light of potentially conflicting instructional goals). We argue that a session focused on building faculty awareness and understanding of an instructional strategy doesn't preclude creating space for these pedagogically-rich conversations within that session. We encourage workshop leaders to consider when and how to start and sustain such conversations.

Though we have shown that physics faculty can engage in pedagogical sense-making, we also know that they likely do not always reason in these productive ways. As we have suggested, it is likely that deliberate framing and specific situational structures lend robustness or stability to such reasoning within groups of physics faculty. We hope to inspire others to pursue additional research regarding what launches and sustains instructors' pedagogical sense-making.

\section{ACKNOWLEDGMENTS}

This work is supported by funding from NSF DUE1431681. We thank Andy Elby for his feedback on this analysis; Ed Prather and Derek Richardson for their support and guidance; and Bob Hilborn and the workshop leader in this study for allowing and encouraging us to do this research.
[1] S. Freeman, S. L. Eddy, and M. McDonough, Proc. Nat. Acad. Sci. U.S.A. 111, 8410-5 (2014).

[2] C. Henderson, A. Beach, and N. Finkelstein, J. Res. Sci. Teach. 48, 952-984 (2011).

[3] C. Henderson, M. Dancy, and M. Niewiadomska-Bugaj, Phys. Rev. ST Phys. Educ. Res. 8, p. 020104 (2012).

[4] C. Goodwin, American Anthropologist 96, 606-633 (1994).

[5] J. E. Coffey, D. Hammer, D. M. Levin, and T. Grant, J. Res. Sci. Teach. 48, 1109-1136 (2011).

[6] R. E. Scherr and R. M. Goertzen, in Recruiting and educating future physics teachers, edited by C. Sandifer and E. Brewe (American Physical Society, College Park, MD, 2015).

[7] A. D. Robertson, R. E. Scherr, and D. Hammer Responsive teaching in science and mathematics (Routledge, 2015).

[8] I. S. Horn and J. W. Little, Am. Educ. Res. J. 47, 181-217 (2010).

[9] P. Aubusson, J. Griffin, and C. M. Steele, Stud. Teach. Educ. 6, 201-216 (2010).

[10] D. L. Ball and D. K. Cohen. In G. Sykes and L. Darling-Hammond (Eds.), Teaching as the learning profession:Handbook of policy and practice (pp. 3-32). (Jossey Bass, San Francisco, 1999).

[11] D. C. Lortie and D. Clement, Schoolteacher: A sociological study (University of Chicago Press, Chicago, IL, 1975).

[12] A. Kezar, ASHE-ERIC higher education report 28, p. 147 (2001).

[13] D. Kember, Learn. and Instr. 7, 255-275 (1997).
[14] D. Hammer, A. Elby, R. E. Scherr, and E. F. Redish, in Transfer of learning from a modern multidisciplinary perspective (Information Age Publishing, Greenwich, CT, 2005).

[15] L. S. Vygotsky, Mind in society: The development of higher psychological processes (Harvard University Press, Cambridge, MA, 1980).

[16] H. Daniels, Vygotsky and research (Routledge, 2008).

[17] M. Cole, Cultural psychology: A once and future discipline (Harvard University Press, 1998).

[18] B. Rogoff, Apprenticeship in thinking: Cognitive development in social context. (Oxford University Press, 1990).

[19] E. Hutchins, Cognition in the wild (MIT press, 1995).

[20] A. Olmstead and C. Turpen, arXiv preprint arXiv:1606.07126 (2016).

[21] S. V. Chasteen, R. Chattergoon, E. E. Prather, and R. Hilborn, in Phys. Educ. Res. Conf. (PER Conference, Sacramento, CA, 2016).

[22] R. Yin. Case Study Research: Design and Methods. (Sage Publications, 2003).

[23] D. Hammer. The Proceedings of the Enrico Fermi Summer School in Physics (Italian Physical Society, 2004).

[24] R. S. Russ and P. Hutchison. ICLS '06 Proceedings of the 7th International Conference on Learning Sciences (2006).

[25] J. C. Corbo, D. L. Reinholz, M. H. Dancy, and S. Deetz, Phys. Rev. Phys. Educ. Res. 12, p. 010113 (2016).

[26] Periscope materials can be accessed at https://www.physport.org/periscope/ 